\section{High pressure redistribution of nitrogen and sulfur during planetary stratification}

\author{
C.R.M. Jackson ${ }^{1 *}$, E. Cottrell ${ }^{2}$, Z. Du $^{3,4}$, N.R. Bennett ${ }^{5}$, Y. Fei ${ }^{6}$
}

Abstract

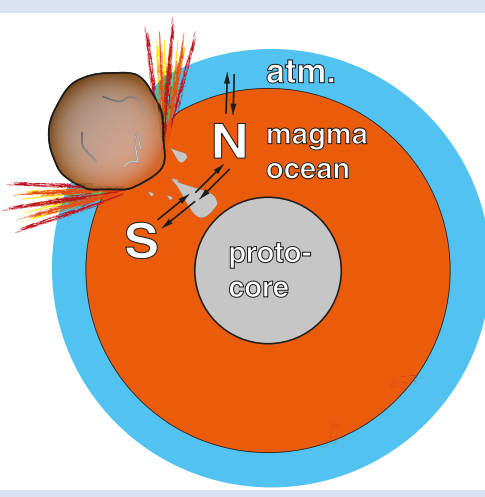

Nitrogen is essential to life, and yet is also the most depleted element in the Earth relative to gas-rich chondrites. A key expression of Earth's $\mathrm{N}$ depletion is its elevated sulfur-nitrogen $(\mathrm{S} / \mathrm{N})$ ratio. Primordial stratification into a core, mantle, and atmosphere is the largest mass transfer process that terrestrial planets experience, but the data required to evaluate how $\mathrm{S} / \mathrm{N}$ ratios respond to primordial stratification of Earth-sized planets do not exist. We report new metal-silicate partitioning experiments on $\mathrm{N}$ up to $26 \mathrm{GPa}$ and $3437 \mathrm{~K}$. Our data indicate that nitrogen becomes more siderophile with increasing pressure and less siderophile with increasing carbon and nickel in the metal phase. We apply our new experiments with literature data for S partitioning to a core formation-primordial atmosphere degassing model. Our model demonstrates that the $\mathrm{S} / \mathrm{N}$ ratio of the observable Earth can be set during primordial stratification under the same extreme $P-T$ conditions that satisfy refractory siderophile element budgets while also yielding a bulk planet with S contents near that estimated from Earth's volatility trend.

Received 7 March 2021 | Accepted 15 July 2021 | Published 7 September 2021

\section{Introduction}

Nitrogen is the most depleted element in the observable Earth when compared to CI chondrites, materials that most faithfully record the bulk composition of the solar system (observable Earth is the sum of the atmosphere, oceans, crust, and mantle) (e.g., Marty, 2012; Halliday, 2013). The depletion of $\mathrm{N}$ is a fundamental expression of the integrated processes that determine the volatile budget of planets (Fig. 1).

There are many early acting processes that can deplete nitrogen and other volatile elements, either in a bulk planet or its observable reservoirs. Chondrites have various volatile element patterns that may reflect formation in regions of the Solar System with fractionated volatiles or the operation of incomplete condensation/evaporation reactions (Bergin et al., 2015). With accretion and differentiation, terrestrial bodies form atmospheres, and these atmospheres can be lost (Tucker and Mukhopadhyay, 2014; Schlichting et al., 2015). Core formation occurs in parallel to planetary accretion, and because nitrogen can display both siderophile and lithophile behaviour, the effect of core formation on the apparent nitrogen depletion in Earth remains uncertain (Roskosz et al., 2013; Kadik et al., 2015; Li et al., 2016; Dalou et al., 2017; Grewal et al., 2019a,b; Speelmanns et al., 2019).
The role of pressure and temperature on core formation chemistry become larger for larger planetary bodies, as indicated by the refractory siderophile element concentrations observed for Earth, Mars, and Vesta (Righter and Drake, 1996). Studies agree that increasing temperature makes nitrogen less siderophile (Grewal et al., 2019a; Speelmanns et al., 2019). Extrapolating the temperature effect on metal-silicate partition coefficients for nitrogen $\left(D_{\mathrm{m} / \mathrm{s}}^{\mathrm{N}}=\left[X_{\text {metal }}^{\mathrm{N}}\right] /\left[X_{\text {silicate }}^{\mathrm{N}}\right]\right.$, atomic) to the average core formation temperature for Earth implies lithophile behaviour (e.g., Speelmanns et al., 2019). In the absence of a large effect of pressure, core formation would apparently have little ability to modify the observable budget of nitrogen during the accretion of larger rocky worlds, such as Earth.

Previously published high pressure experiments suggest that pressure favours $\mathrm{N}$ incorporation into cores (Roskosz et al., 2013, Grewal et al., 2019a); however, the pressure effect cannot be confidently resolved to be different from zero (Grewal et al., 2019a). Towards this end, we report $D_{\mathrm{m} / \mathrm{s}}^{\mathrm{N}}$ values from experiments conducted up to $26 \mathrm{GPa}$ and $3437 \mathrm{~K}$, using a laser heated diamond-anvil cell (LH-DAC). We supplement our LH-DAC data, with a systematic series of piston cylinder experiments to enable a robust parameterisation.

\footnotetext{
. Department of Earth and Environmental Sciences, Tulane University, 6823 St. Charles Avenue, New Orleans, LA 70118, USA

2. Department of Minerals Sciences, National Museum of Natural History, Smithsonian Institution, 10th and Constitution Ave NW, Washington D.C. 20560, USA

State Key Laboratory of Isotope Geochemistry, Guangzhou Institute of Geochemistry, Chinese Academy of Sciences, Guangzhou, China

CAS Center for Excellence in Deep Earth Sciences, Guangzhou, 510640, China

Department of Earth Sciences, University of Toronto, 22 Russell St, Toronto, ON M5S 3B1, Canada

Earth and Planets Laboratory, Carnegie Institution for Science, 5241 Broad Branch Rd NW, Washington D.C. 20015, USA

Corresponding author (email: cjackson2@tulane.edu)
} 


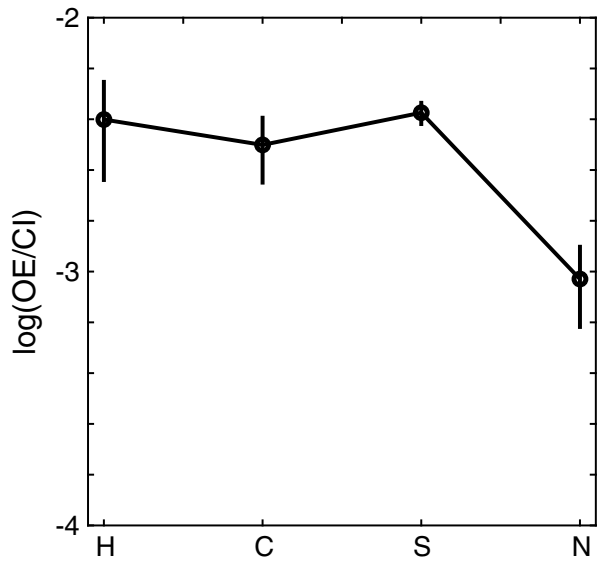

Figure 1 Concentrations of volatile elements $(H, C, S$, and $N)$ in Earth's observable reservoirs normalised to $\mathrm{Cl}$ chondrites. Nitrogen appears depleted in Earth compared to other volatiles. Data are from Hirschmann (2016) and Wasson and Kallemeyn (1988).

\section{Methods}

We conducted lower $P$ - T partitioning experiments (1773-2413 K, 0.95-2.38 GPa) using a piston cylinder (PC) and higher $P-T$ experiments (3046-3437 K, 23.2-25.6 GPa) using a LH-DAC (Tables 1, S-1). Experimental $\mathrm{fO}_{2}$ conditions ranged from $\Delta \mathrm{IW}$ -6.6 to $\Delta \mathrm{IW}-1.0$ (log unit deviations from the iron-wüstite buffer). We quantified the composition of reacted metal-silicate pairs using field emission electron microprobe analysis (Table 1). An example backscatter image is provided in Figure S-1, along with a typical time-temperature path for LH-DAC experiments. We also compare major element partitioning data of $\mathrm{LH}-$ DAC experiments to literature data in Figure S-2 as an evaluation of data quality. Table S-2 reports starting materials compositions. Further details on methods are provided in the Supplementary Information.

\section{Results}

We completed independent series of experiments to quantify the $P$-T-X controls on $D_{\mathrm{m} / \mathrm{s}}^{\mathrm{N}}$ values (Fig. 2, Table 1). Individual series correlations indicate $D_{\mathrm{m} / \mathrm{s}}^{\mathrm{N}}$ values depend strongly on $\mathrm{fO}_{2}\left(R^{2}=0.99, \mathrm{p}\right.$ value $\left.=0.005, n=4\right)$, temperature $\left(R^{2}=0.97\right.$, $\mathrm{p}$ value $=0.001, n=6)$, and pressure $\left(R^{2}=0.98\right.$, $\mathrm{p}$ value $<0.001$, $n=9$ ) over other conditions relevant to magma oceans (Fig. 2a,d), whereas $X_{\text {metal }}^{\mathrm{C}} X_{\text {metal }}^{\mathrm{Ni}}, X_{\text {metal }}^{\mathrm{S}}$ and the ionic porosity of silicate liquid have significant ( $\mathrm{p}$ values $<0.05)$ but minor effects (Figs. 2b,c, S-4, S-5). Our $\mathrm{fO}_{2}$ and temperature findings accord with previous work (Dalou et al., 2017; Grewal et al., 2019a; Speelmanns et al., 2019). Our lower pressure experiments indicate that $\mathrm{N}-\mathrm{C}$ interactions in Fe alloy make both elements less siderophile and yield an epsilon value $\left(\varepsilon_{\mathrm{C}}^{\mathrm{N}}\right)$ of $7.6 \pm 1.4\left(R^{2}=0.90\right.$, $\mathrm{p}$ value $=0.004, n=6$; Fig. S-4), qualitatively consistent with the Steelmaking Data Sourcebook (1988) and $D_{\mathrm{m} / \mathrm{s}}^{\mathrm{N}}$ values collected under C-free conditions (Grewal et al., 2021). Our $\boldsymbol{\varepsilon}$ value calculations follow the approach of Ma (2001).

Our LH-DAC experiments consistently demonstrated siderophile behaviour (Fig. 2d) despite their high temperature, and this requires a large, positive pressure effect. These high $P$ - $T$ experiments contain $\mathrm{C}$ and $\mathrm{Ni}$, and were relatively oxidising. Quantifying the pressure effect therefore requires simultaneous consideration of these other parameters, which is enabled by our PC experiments (Eq. 1, see below). Our determination of a positive effect of pressure is consistent with previous work, but the larger range of $P$ we investigated results in more precise determination of the $P$-T coefficients in Equations 1 and 2 (c.f., Roskosz et al., 2013, Grewal et al., 2019a).

To parameterise our data, we first recalculate experiments to a carbon-free baseline using our newly derived $\varepsilon_{C}^{\mathrm{N}}$ value. We then conduct an equal weight, least squares regression on parameters identified as significant in their individual series $\left(1 / T, P / T, X_{\text {metal }}^{\varepsilon \mathrm{Ni}}, X_{\text {metal }}^{\varepsilon \mathrm{S}}\right.$, and $\left.\Delta \mathrm{IW}\right)$. Our approach yields the following expression $\left(R^{2}=0.95\right.$, p value $<0.001, n=22$; Fig. 2 e):

$$
\begin{aligned}
\log \left(D_{\mathrm{m} / \mathrm{s}}^{\mathrm{N}, \mathrm{C}-\text { free }}\right)= & 6172 \pm 9541 / T+222 \pm 33 \mathrm{P} / \mathrm{T} \\
& +5.08 \pm 1.42 X_{\text {metal }}^{\varepsilon \mathrm{Ni}}+1.52 \pm 0.72 X_{\text {metal }}^{\varepsilon \mathrm{S}}+0.59 \\
& \pm 0.04 \Delta \mathrm{IW}-0.55 \pm 0.48-\log \left(\gamma_{\text {metal }}^{\mathrm{Fe}}\right) \quad \text { Eq. } 1
\end{aligned}
$$

or if the effect of carbon is included in the parameterisation

$$
\begin{aligned}
\log \left(D_{\mathrm{m} / \mathrm{s}}^{\mathrm{N}}\right)= & 6172 \pm 9541 / T+222 \pm 33 P / T+5.08 \\
& \pm 1.42 X_{\text {metal }}^{\varepsilon \mathrm{Ni}}+1.52 \pm 0.72 X_{\text {metal }}^{\varepsilon \mathrm{S}} \\
& +7.61 \pm 1.41 X_{\text {metal }}^{\varepsilon \mathrm{C}}+0.59 \pm 0.04 \Delta \mathrm{IW} \\
& -0.55 \pm 0.48-\log \left(\gamma_{\text {metal }}^{\mathrm{Fe}}\right)
\end{aligned}
$$

Uncertainties are reported as $1 \sigma$. Note that $X_{\text {metal }}^{\varepsilon N i}, X_{\text {metal }}^{\varepsilon S}$ and $X_{\text {metal }}^{\varepsilon \mathrm{C}}$ refer to the expanded concentration expression associated with the $\varepsilon$ notation of Ma (2001), and that positive coefficients indicate a reduction in the $D_{\mathrm{m} / \mathrm{s}}^{\mathrm{N}}$ value. Application of Equation 1 to a mantle liquidus geotherm at $\Delta \mathrm{IW}-2$ indicates a monotonic increase in $D_{\mathrm{m} / \mathrm{s}}^{\mathrm{N}}$ with depth (Fig. 2f).

We parameterise our data alone because we completed systematic series of experiments to isolate specific effects on partitioning. Inclusion of all published data is accompanied by a large number of free parameters, and prevents resolution of $\mathrm{N}, \mathrm{S}$ and $\mathrm{C}$ effects that are clearly observable in our results (Figs. 2, S-4). Predictions of Equation 1 are compared to literature data in Figures 2e, S-6. Additional details regarding this regression are provided in the Supplementary Information. The covariance matrix for Equation 1 is reported in Table S-3. We also report our fitting of literature data with the effects identified as significant here as Equation S-7.

\section{Modelling N Distribution throughout Earth}

Having established that pressure strongly modulates $D_{\mathrm{m} / \mathrm{s}}^{\mathrm{N}}$ values, we now calculate the equilibrium distribution of $\mathrm{N}$ and $\mathrm{S}$ between cores, magma oceans, and atmospheres for a range of plausible stratification conditions. We include $\mathrm{S}$ because multiple high pressure studies show agreement and now constrain its metal-silicate partitioning up to extreme $P$ - $T$ conditions. Our parameterisation of $D_{\mathrm{m} / \mathrm{s}}^{\mathrm{S}}$ values is applied here and is detailed in the Supplementary Information (Fig. S-8).

Mass balance is used to solve for the equilibrium distribution of $\mathrm{N}$ and $\mathrm{S}$ as required by partitioning and magma solubility constraints (Eq. 1; Libourel et al., 2003). The mantle is assumed to be completely molten, and the mass fraction of the core is 0.325 . Uncertainties are evaluated by varying $D_{\mathrm{m} / \mathrm{s}}^{\mathrm{N}}$ and $D_{\mathrm{m} / \mathrm{s}}^{\mathrm{S}}$ according to their covariance matrices and iterating the mass balance model. No S is assumed to be present in the atmosphere given its relatively high solubility in magma. All scenarios assume a bulk planet $\mathrm{S} / \mathrm{N}$ ratio set by enstatite chondrite (85) and that the magma ocean contains $225 \pm 25$ ppm S (Hirschmann, 2016). We focus on enstatite chondrites because their average $\mathrm{S} / \mathrm{N}$ ratio 


\begin{tabular}{|c|c|c|}
\hline 3 & $\underset{\substack{n \\
i}}{i}$ & 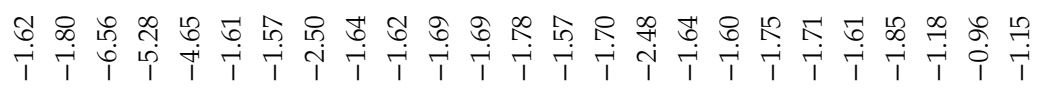 \\
\hline 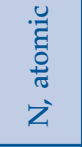 & 吾 & 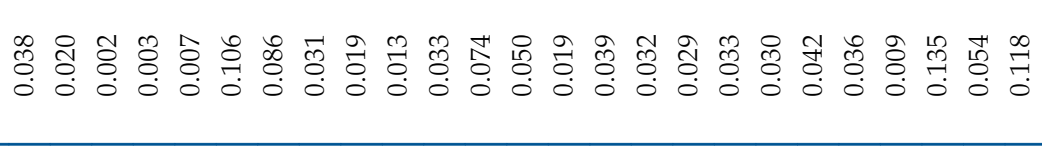 \\
\hline 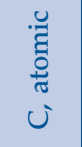 & 常 & 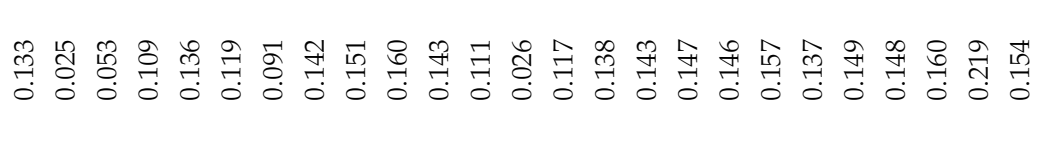 \\
\hline 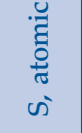 & $\begin{array}{ll}0 \\
0 \\
0 \\
0\end{array}$ & 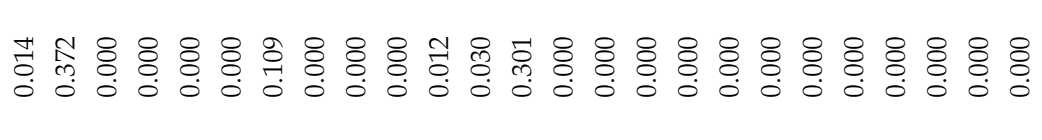 \\
\hline 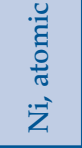 & $\stackrel{8}{\circ}$ & 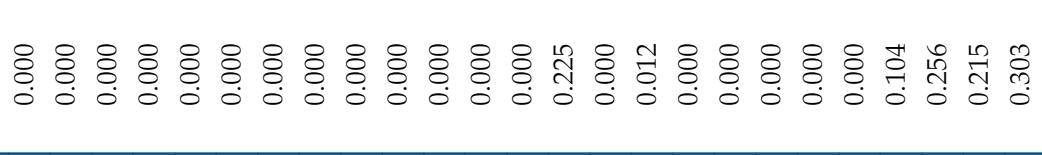 \\
\hline 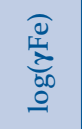 & $\begin{array}{l}\infty \\
0 \\
0 \\
1\end{array}$ & 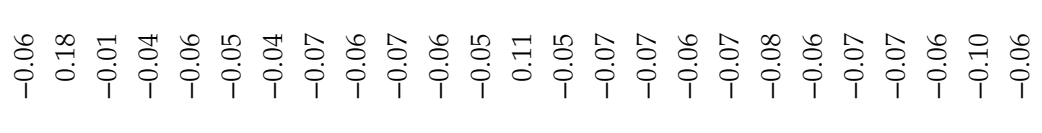 \\
\hline 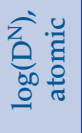 & $\stackrel{i}{i}$ & 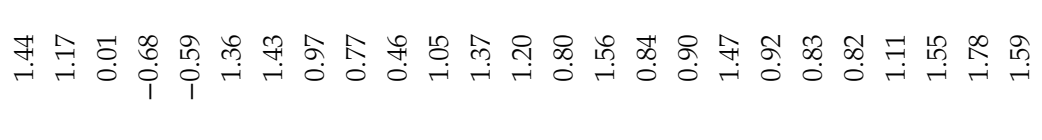 \\
\hline$\stackrel{+1}{2}$ & $\stackrel{20}{\circ}$ & 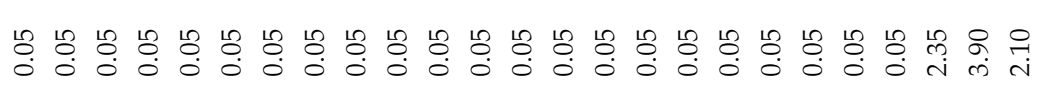 \\
\hline $\begin{array}{l}\stackrel{\sigma}{0}^{2} \\
\varepsilon^{\prime}\end{array}$ & $\stackrel{2}{2}$ & ஜ \\
\hline$\stackrel{+1}{+}$ & $\stackrel{\circ}{\circ}$ & 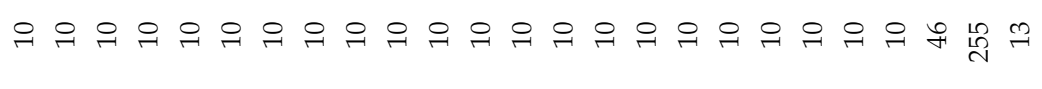 \\
\hline 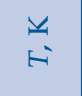 & & 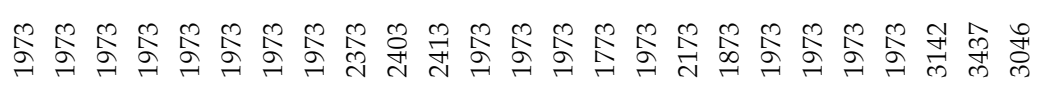 \\
\hline : & $\begin{array}{l}\operatorname{li}_{2}= \\
\text { si } \\
\text { in } \\
\text { aizi }\end{array}$ & 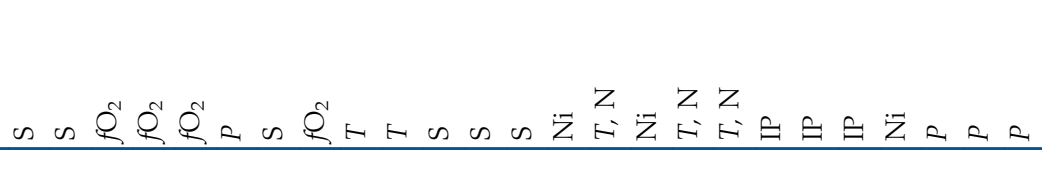 \\
\hline zัّ & & 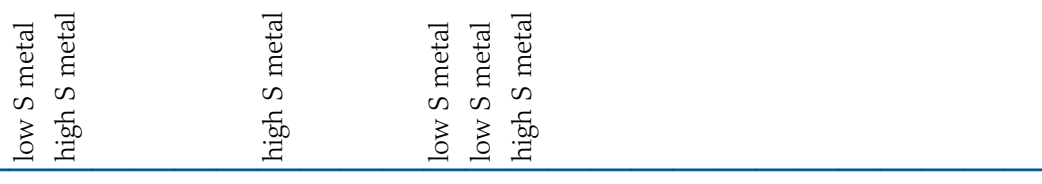 \\
\hline 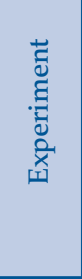 & $\begin{array}{l}\vec{i} \\
\text { ir } \\
z_{1} \\
u \\
i_{1}\end{array}$ & 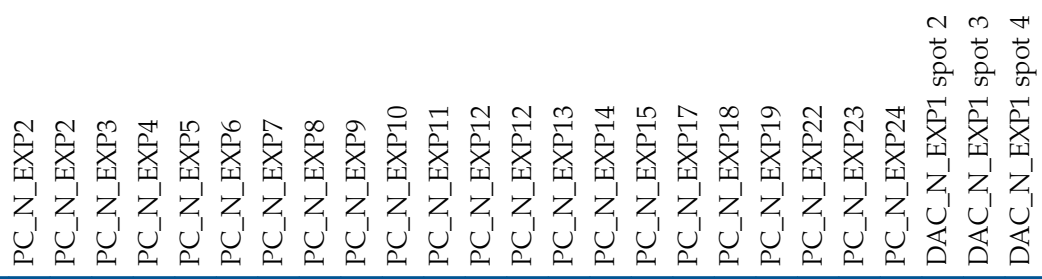 \\
\hline
\end{tabular}



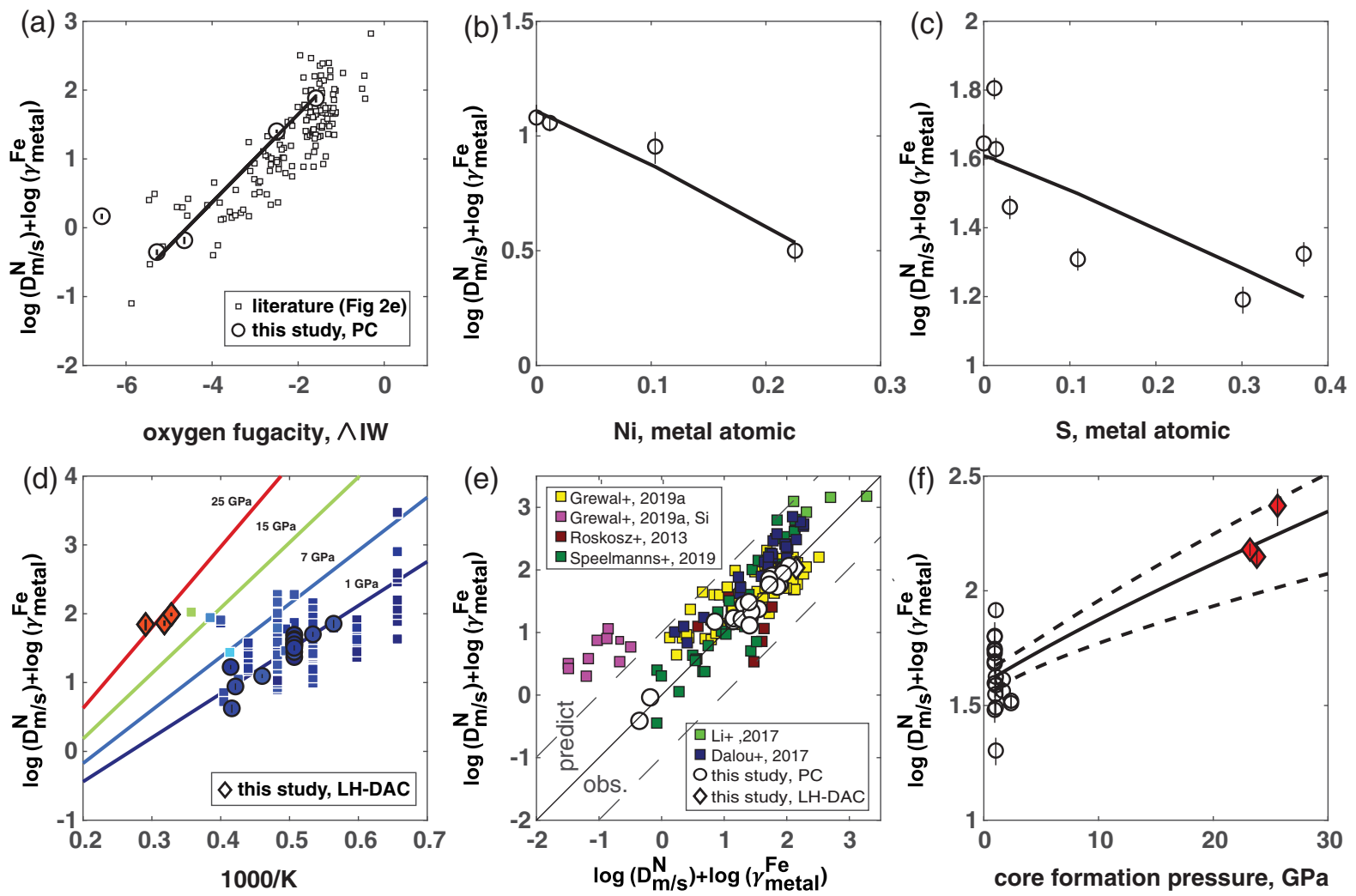

Figure 2 Controls on nitrogen partitioning. (a) Oxidising conditions make nitrogen more siderophile. Literature data are recalculated to $1973 \mathrm{~K}$ and $1 \mathrm{GPa}$. (b) Nickel and (c) Sulfur make nitrogen less siderophile. (d) Hotter temperatures make nitrogen less siderophile. Extrapolation of temperature effect at $1 \mathrm{GPa}$ underpredicts $D_{\mathrm{m} / \mathrm{s}}^{\mathrm{s}}$ values compared to values measured for higher pressure LH-DAC experiments. (e) A 1:1 comparison of $D_{\mathrm{m} / \mathrm{s}}^{\mathrm{N}}$ observations versus predictions from Equation 1 . The $R^{2}$ for the literature fit is 0.76 . (f) Application of Equation 1 to mantle liquidus geotherm at $\Delta \mathrm{IW}-2$. Nitrogen becomes more siderophile with depth.

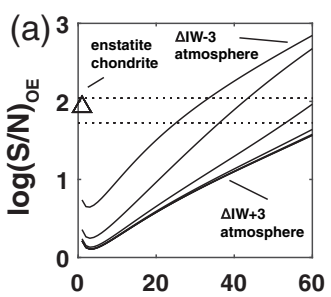

Core formation $\mathrm{P}, \mathrm{GPa}$

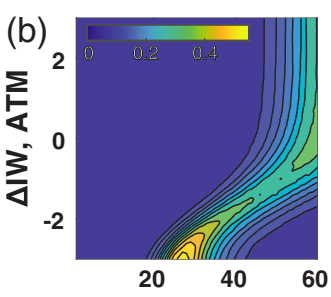

Core formation P, GPa

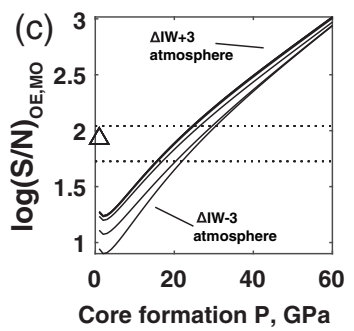

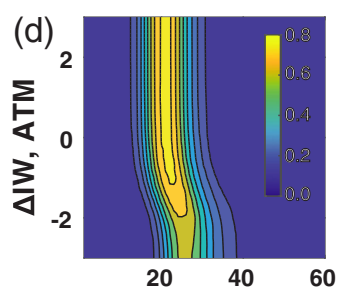

Core formation P, GPa

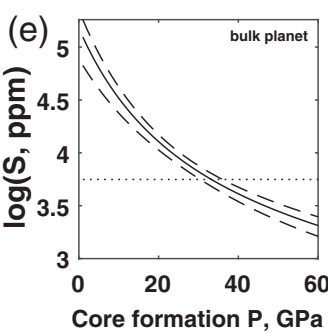

Figure 3 Models for redistribution of $\mathrm{N}$ and $\mathrm{S}$ in response to planetary differentiation. (a) An example of a model iteration of $\mathrm{S} / \mathrm{N}_{\mathrm{OE}}$ as function of core formation pressure and atmospheric $\mathrm{fO}_{2}$. Solid lines are model solutions for a given atmospheric $\mathrm{fO}_{2}$ (log unit spacing). Horizontal dotted lines delineate the estimated range of $\mathrm{S} / \mathrm{N}_{\mathrm{OE}}$ for Earth (Hirschmann, 2016). Observable Earth is the sum of the atmosphere and magma ocean. (b) Fractional success of the model between iterations for producing a $\mathrm{S} / \mathrm{N}_{\mathrm{OE}}$ ratio that matches Earth. (c) An example of a model iteration of $\mathrm{S} / \mathrm{N}_{\mathrm{OE} . \mathrm{MO}}$ as function of core formation pressure and atmospheric $\mathrm{fO}_{2}$. Horizontal dotted lines delineate the estimated range of $\mathrm{S} / \mathrm{N}_{\mathrm{OE}}$ for Earth. Observable Earth is only the magma ocean. (d) Fractional success of the model between iterations for producing a $\mathrm{S} / \mathrm{N}_{\mathrm{OE}}$ ratio that matches Earth. (e) Predicted bulk planet $\mathrm{S}$ as a function of core formation pressure. Dashed lines are 1 sigma that propagate uncertainties from the observable Earth $\mathrm{S}$ and parameterised $D_{\mathrm{m} / \mathrm{s}}^{\mathrm{s}}$ values. The dotted line is the estimate of observable Earth $\mathrm{S}$ from the volatility trend (5600 ppm; Dreibus and Palme, 1996).

is intermediate between gas-rich (29; CI and CM) and ordinary chondrites (404; Wasson and Kallemeyn, 1988). Models that consider $\mathrm{S} / \mathrm{N}$ ratios for other groups of chondrites are presented in the Supplementary Information (Figs. S-9, S-10).

Our first goal is to quantify how the $\mathrm{S} / \mathrm{N}$ ratio of observable Earth $\left(\mathrm{S} / \mathrm{N}_{\mathrm{OE}}, 82 \pm 29\right.$, dotted lines in Fig. 3a, $)$ varies in response to differentiation conditions. We consider models with core formation $\mathrm{fO}_{2}$ of $\Delta \mathrm{IW}-2$ while varying core formation pressure and atmospheric $\mathrm{fO}_{2}$ (Fig. 3). We focus on $\Delta \mathrm{IW}-2$ because the $\mathrm{FeO}$ content of Earth implies an average $\mathrm{fO}_{2}$ for core formation near this value. Pressures of metal-silicate equilibration range up to $60 \mathrm{GPa}$, an upper limit in the single stage framework for Earth (e.g., Fischer et al., 2015). Our model takes a single stage approach, and while accretion is a multi-step process, single stage calculations capture average $P-T-X$ conditions that can be readily compared between elements (Siebert et al., 2011). Atmospheric $\mathrm{fO}_{2}$ varies in our model between $\Delta \mathrm{IW}-3$ and $\Delta \mathrm{IW}+3$. Atmospheric $\mathrm{fO}_{2}$ conditions are a free parameter in light of evidence for the depth dependence of the $\mathrm{Fe}^{+3} / \mathrm{Fe}_{\text {tot }}$ ratio of magma in equilibrium with iron (Zhang et al., 2017; 
Armstrong et al., 2019; Deng et al., 2020) and the temperature dependence of $\mathrm{Fe}^{+3} / \mathrm{Fe}_{\text {tot }}$ for any $\mathrm{fO}_{2}$ (Sossi et al., 2020).

Our models demonstrate the strong sensitivity of $\mathrm{S} / \mathrm{N}_{\mathrm{OE}}$ ratios to core formation pressure; at low pressure $(<10 \mathrm{GPa})$, $\mathrm{S} / \mathrm{N}_{\mathrm{OR}}$ ratios are low, but with increasing pressure, $\mathrm{S} / \mathrm{N}_{\mathrm{OE}}$ ratios rise as $\mathrm{S}$ becomes less siderophile and $\mathrm{N}$ becomes more siderophile. The rise is such that core formation near 30 GPa results in $\mathrm{S} / \mathrm{N}_{\mathrm{OE}}$ ratios that match Earth for more reducing atmospheres. More oxidising atmospheres require higher pressure core formation to satisfy Earth's $\mathrm{S} / \mathrm{N}_{\mathrm{OE}}$ ratio, as more $\mathrm{N}$ remains in the atmosphere, unable to partition into the core (Fig. 3a,b).

It is possible that the atmosphere is partially lost during accretion, leading to preferential depletion of $\mathrm{N}$ relative to $\mathrm{S}$. We model this possibility as the end member of the magma ocean being the only contributor of $\mathrm{N}$ and $\mathrm{S}$ to later-forming observable reservoirs (Fig. $3 \mathrm{c}, \mathrm{d}$ ). In these cases $\mathrm{S} / \mathrm{N}_{\mathrm{OE}, \mathrm{MO}}(\mathrm{S} / \mathrm{N}$ ratio of the magma ocean) also matches Earth near $30 \mathrm{GPa}$, and model results are relatively insensitive to atmospheric $\mathrm{fO}_{2}$ Cases of intermediate atmospheric loss plot between the two end members for atmospheric contribution considered here (c.f., Fig. 3a-d).

Taken together, our models demonstrate that higher pressure core formation scenarios can satisfy the $\mathrm{S} / \mathrm{N}_{\mathrm{OE}}$ ratio of Earth, assuming a bulk planet $\mathrm{S} / \mathrm{N}$ ratio similar to enstatite chondrite. Bulk planet $\mathrm{S} / \mathrm{N}$ ratios closer to gas-rich chondrites (low $\mathrm{S} / \mathrm{N}$ ) require even higher core formation pressures, while bulk planet $\mathrm{S} / \mathrm{N}$ ratios closer to ordinary chondrites (high $\mathrm{S} / \mathrm{N}$ ) require lower pressure to satisfy the $\mathrm{S} / \mathrm{N}_{\mathrm{OE}}$ ratio constraint (Figs. S-9, S-10). This all serves to highlight the importance of core formation pressure for modulating planetary volatile budgets.

It is significant that higher pressure core formation (>30 GPa) and a core-mantle $f_{2}$ of $\Delta \mathrm{IW}-2$ can produce $\mathrm{S} / \mathrm{N}_{\mathrm{OE}}$ ratios equal to Earth because these are the same differentiation conditions implied by moderately siderophile element and $\mathrm{FeO}$ concentrations in the observable Earth in a single stage framework (e.g., Siebert et al., 2011; Fischer et al., 2015). Importantly, higher pressure core formation also yields a bulk planet with 6650-2050 ppm S (30-60 GPa) (Fig. 3e), and these values compare favourably with estimates of $5600 \mathrm{ppm} \mathrm{S}$ for bulk Earth based on the volatility trend (Dreibus and Palme, 1996). The multiple successes of higher pressure models for explaining Earth's volatile budget are important because they suggest that volatiles are modulated by the same core formation events that modulate refractory elements. This suggestion contrasts with previous hypotheses that smaller, volatile-rich bodies preferentially contributed to Earth's volatile budget (e.g., Grewal et al., 2019b), decoupling the accretion of life-enabling elements from refractory elements

It is well established within the Solar System that planetary body size correlates with average core formation pressures (Righter and Drake, 1996), and our work therefore predicts a direct relationship between planet size and its distribution of volatiles. This link should enable more precise evaluations of exoplanet habitability, worlds for which size remains a central constraint on their geologic evolution.

\section{Acknowledgements}

We acknowledge discussions with Ian Ocampo during a summer internship at NMNH. We additionally acknowledge the support provided by C. Prescher, E. Greenberg, and V. Prakapenka during the experiments conducted at GSECARS and in data reduction. We thank Rob Wardell and Tim Rose for their support of the microscopy work associated with this manuscript. We thank Tim McCoy for discussions regarding the model results.

CRMJ acknowledges support by NSF-EAR grant 1725315 , NASA grant 80NSSC21K0377, Smithsonian GVP fellowship, Carnegie Institution for Science (Geophysical Lab) Fellowship, and start up from Tulane University. Experiments were partially supported by NASA grant to YF. ZD thanks the support from Carnegie Fellowship, grants from Chinese Academy of Sciences and State Key Laboratory of Isotope Geochemistry (No. 29Y93301701, 51Y8340107), as well as Strategic Priority Research Program (B) (XDB18030604). Portions of this work were performed at GeoSoilEnviroCARS (The University of Chicago, Sector 13), the Advanced Photon Source, Argonne National Laboratory. GeoSoilEnviroCARS is supported by the National Science Foundation-Earth Sciences (EAR 1128799) and the Department of Energy-GeoSciences (DE-FG0294ER14466). This research used resources of the Advanced Photon Source, a US Department of Energy (DOE) Office of Science User Facility operated for the DOE Office of Science by Argonne National Laboratory under contract number DEAC02-06CH11357.

Editor: Cin-Ty Lee

\section{Additional Information}

Supplementary Information accompanies this letter at https:// www.geochemicalperspectivesletters.org/article2122.

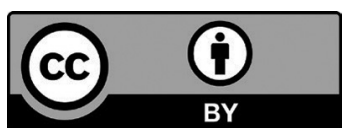

(C) 2021 The Authors. This work is distributed under the Creative Commons Attribution 4.0 License, which permits unrestricted use, distribution, and reproduction in any medium, provided the original author and source are credited. Additional information is available at http://www.geochemicalperspectivesletters.org/ copyright-and-permissions.

Cite this letter as: Jackson, C.R.M., Cottrell, E., Du, Z., Bennett, N.R., Fei, Y. (2021) High pressure redistribution of nitrogen and sulfur during planetary stratification. Geochem. Persp. Let. 18, 37-42.

\section{References}

Armstrong, K., Frost, D.J., McCammon, C.A., Rubie, D.C., Ballaran, T.B. (2019) Deep magma ocean formation set the oxidation state of earth's mantle. Science 365, 903-906.

Bergin, E.A., Blake, G.A., Ciesla, F., Hirschmann, M.M., Li, J. (2015) Tracing the ingredients for a habitable earth from interstellar space through planet formation. Proceedings of the National Academy of Sciences 112, 8965-8970.

Dalou, C., Hirschmann, M.M., von der Handt, A., Mosenfelder, J., Armstrong, L.S. (2017) Nitrogen and carbon fractionation during core-mantle differentiation at shallow depth. Earth and Planetary Science Letters 458, 141-151.

Deng, J., Du, Z., Karki, B., Ghosh D., Lee, K. (2020) A magma ocean origin to divergent redox evolutions of rocky planetary bodies and early atmospheres. Nature Communications 11, 2007.

Dreibus, G., Palme, H. (1996) Cosmochemical constraints on the sulfur content in the Earth's core. Geochimica et Cosmochimica Acta 60, 1125-1130.

Fischer, R.A., Nakajima, Y., Campbell, A.J., Frost, D.J., Harries, D., Langenhorst, F., Miyajima, N., PolloK, K., Rubie, D.C. (2015) High pressure metal-silicate partitioning of $\mathrm{Ni}, \mathrm{Co}, \mathrm{V}, \mathrm{Cr}, \mathrm{Si}$, and $\mathrm{O}$. Geochimica et Cosmochimica Acta 167, 177-194.

Grewal, D.S., DasGuPta, R., Holmes, A.K., Costin, G., Li, Y., Tsuno, K. (2019a) The fate of nitrogen during core-mantle separation on earth. Geochimica et Cosmochimica Acta 251, 87-115.

Grewal, D.S., Dasgupta, R., Sun, C., Tsuno, K., Costin, G. (2019b) Delivery of carbon, nitrogen, and sulfur to the silicate earth by a giant impact. Science Advances 5, eaau3669. 
Grewal, D.S., Dasgupta, R., Hough, T., Farnell, A. (2021) Rates of protoplanetary accretion and differentiation set nitrogen budget of rocky planets. Nature Geoscience 14, 369-376.

Halliday, A.N. (2013) The origins of volatiles in the terrestrial planets. Geochimica et Cosmochimica Acta 105, 146-171.

HiRsChMANn, M.M. (2016) Constraints on the early delivery and fractionation of Earth's major volatiles from $\mathrm{C} / \mathrm{H}, \mathrm{C} / \mathrm{N}$, and $\mathrm{C} / \mathrm{S}$ ratios. American Mineralogist 101, 540-553.

Kadik, A., Koltashev, V., Kryukova, E., Plotnichenko, V., Tsekhonya, T, Kononkova, N. (2015) Solubility of nitrogen, carbon, and hydrogen in $\mathrm{FeO}-\mathrm{Na}_{2} \mathrm{O}-\mathrm{Al}_{2} \mathrm{O}_{3}-\mathrm{SiO}_{2}$ melt and liquid iron alloy: Influence of oxygen fugacity. Geochemistry International 53, 849-868.

Li, Y., Marty, B., ShcheKA, S., Zimmermann, L., Keppler, H. (2016) Nitrogen isotope fractionation during terrestrial core-mantle separation. Geochemical Perspectives Letters 2, 138-147.

Libourel, G., Marty, B., Humbert, F. (2003) Nitrogen solubility in basaltic melt. Part I. Effect of oxygen fugacity. Geochimica et Cosmochimica Acta 67, 4123-4135.

MA, Z. (2001) Thermodynamic description for concentrated metallic solutions using interaction parameters. Metallurgical and Materials Transactions $B$ $32,87-103$.

MARTY, B. (2012) The origins and concentrations of water, carbon, nitrogen and noble gases on earth. Earth and Planetary Science Letters 313-314, 56-66.

Righter, K., DraKe, M.J. (1996) Core formation in Earth's moon, Mars, and Vesta. Icarus $124,513-529$.

Roskosz, M., BOUHIFd, M.A., JepHCoat, A.P., Marty, B, Mrsen, B.O. (2013) Nitrogen solubility in molten metal and silicate at high pressure and temperature. Geochimica et Cosmochimica Acta 121, 15-28.

Schlichting, H.E., SARI, R., Yalinewich, A. (2015) Atmospheric mass loss during planet formation: The importance of planetesimal impacts. Icarus 247,

Speelmanns, I.M., Schmidt, M.W., LiebSKE, C. (2019) The almost lithophile character of nitrogen during core formation. Earth and Planetary Science Letters 510, 186-197.

Siebert, J., Corgne, A., Ryerson, F.J. (2011) Systematics of metal-silicate partitioning for many siderophile elements applied to earth's core formation. Geochimica et Cosmochimica Acta 75, 1451-1489.

Sossi, P.A., Burnham, A.D., Badro, J., Lanzirotti, A., Newville, M., O’Neill, H.S.C (2020) Redox state of earth's magma ocean and its venus-like early atmosphere. Science Advances 6, eabd1387.

Steelmaking Data Sourcebook (1988) The Japan Society for the Promotion of Science: The 19th Committee on Steelmaking. Gordon and Breach Science Publishers, New York.

TUCKER, J.M., MuKHOPADHYAY, S. (2014) Evidence for multiple magma ocean outgassing and atmospheric loss episodes from mantle noble gases. Earth and Planetary Science Letters 393, 254-265.

Wasson, J.T., Kallemeyn, G.W. (1988) Compositions of chondrites. Philosophical Transactions of the Royal Society of London Series A, Mathematical and Physical Sciences 325, 535-544.

Zhang, H., Hirschmann, M., Cottrell, E., Withers, A. (2017) Effect of pressure on $\mathrm{Fe}^{3+} / \mathrm{Fe}$ ratio in a mafic magma and consequences for magma ocean redox gradients. Geochimica et Cosmochimica Acta 204, 83-103. 